\title{
MODELLING STOCHASTIC VOLATILITY IN ASSET RETURNS USING FRACTIONALLY INTEGRATED SEMIPARAMETRIC TECHNIQUES
}

\author{
Guglielmo Maria Caporale \\ Brunel University, London
}

\author{
Luis A. Gil-Alana \\ University of Navarra
}

\begin{abstract}
June 2005
Abstract

In this article we estimate the order of integration of the volatility process of several exchange rates and stock returns using fractionally integrated semiparametric techniques, namely a local Whittle semiparametric estimator. The results suggest that all series can be well described in terms of $I(d)$ statistical models, with values of $d$ higher than 0 , indicating long-memory behaviour.
\end{abstract}

Keywords: $\quad$ Fractional Integration, Semiparametric Estimation, Volatility, Asset Returns JEL Classification: C22, G12

Corresponding author: Professor Guglielmo Maria Caporale, Brunel Business School, Brunel University, Uxbridge, Middlesex UB8 3PH, UK. Tel.: +44 (0)1895 266713. Fax: +44 (0)1895 269770. Email: Guglielmo-Maria.Caporale@brunel.ac.uk

The second-named author gratefully acknowledges financial support from the PIUNA Project at the University of Navarra. 


\section{Introduction}

High volatility in asset returns is a well known stylised fact. However, there is no agreement amongst researchers about the best statistical approach to model this type of behaviour. Bollerslev et al. (1992, 1994) proposed ARCH/GARCH models in which the variance of the time series conditional on the previous information is known. On the other hand, Harvey et al. (1994), Ruiz (1994), Hansen (1995) adopted stochastic volatility models where the variance is random. Other similar models, also assuming nonstationarity of the volatility process, are reviewed in Bollerslev et al. (1994). Much of the criticism about nonstationarity in volatility is based on the fact that the process usually has a large negative moving average root, and standard unit root tests (Dickey and Fuller, 1979, Phillips and Perron, 1988, etc.) are known to suffer from extreme size distortions in the presence of MA roots (see, eg. Schwert, 1989; Pantula, 1991). Wright (1999) applies to the log of the squared return series new unit root tests introduced by Perron and Ng (1996), which are robust to large negative MA roots. However, the new tests still reject strongly the hypothesis of nonstationarity in the volatility process, indicating considerable persistence in volatility, which, Wright (1999) suggests, might be better captured using AR(p) specifications with a large AR root or fractionally integrated I(d) models. Following his suggestion, in this paper we take such an approach and model the volatility of several exchange rates and stock prices returns by means of fractional integration techniques. Specifically, we use a semiparametric procedure due to Robinson (1995a), which is briefly described in Section 2. In Section 3 this procedure is applied to the log of the squared returns, while Section 4 contains some concluding comments. 


\section{A local Whittle semiparametric approach}

For the purpose of the present paper, we define an $\mathrm{I}(0)$ process $\left\{\mathrm{u}_{\mathrm{t}} \mathrm{t}=0, \pm 1, \ldots\right\}$, as a covariance stationary process with a spectral density function that is positive and finite at the zero frequency. In this context, we say that $\left\{\mathrm{x}_{\mathrm{t}}, \mathrm{t}=0, \pm 1, \ldots\right\}$ is $\mathrm{I}(\mathrm{d})$ if

$$
\begin{gathered}
(1-L)^{d} x_{t}=u_{t}, \quad t=1,2, \ldots, \\
x_{t}=0, \quad t \leq 0,
\end{gathered}
$$

where the polynomial in (1) can be expressed in terms of its Binomial expansion, such that, for all real d,

$$
(1-L)^{d}=1-d L+\frac{d(d-1)}{2 !} L^{2}-\frac{d(d-1)(d-2)}{3 !} L^{3}+\ldots
$$

Clearly, if $d=0$ in (1), $x_{t}=u_{t}$, and $x_{t}$ is said to exhibit 'short memory', as opposed to the case of 'long memory' occurring when $\mathrm{d}>0$. In essence, there are two main approaches to estimating the fractional differencing parameter. One is parametric, with the model being specified up to a finite number of parameters. Thus, a functional form for the $u_{t}$ in (1) has to be chosen. The other is semiparametric, with $\mathrm{u}_{\mathrm{t}}$ being allowed to follow any $\mathrm{I}(0)$ process. A problem with parametric approaches is that they require the model to be correctly specified. Otherwise, the estimates are liable to be inconsistent. In fact, misspecification of the short-run components of the series may invalidate the estimation of d. Therefore, adopting semiparametric procedures might be advantageous. In this article, we use such a procedure, namely a local Whittle estimator (Robinson, 1995a) which we now describe. 
Robinson's (1995a) estimator is essentially a local "Whittle estimator" in the frequency domain, with a band of frequencies that degenerates to zero. The estimator is implicitly defined by:

$$
\begin{aligned}
& d_{1}=\arg \min _{d}\left(\log \overline{C(d)}-2 d \frac{1}{m} \sum_{j=1}^{m} \log \lambda_{j}\right), \\
& \overline{C(d)}=\frac{1}{m} \sum_{j=1}^{m} I\left(\lambda_{j}\right) \lambda_{j}^{2 d}, \quad \lambda_{j}=\frac{2 \pi j}{T}, \frac{m}{T} \rightarrow 0,
\end{aligned}
$$

for $\mathrm{d} \in(-0.5,0.5){ }^{1}$ Under finiteness of the fourth moment and other mild conditions, Robinson (1995a) proved that:

$$
\sqrt{m}\left(\hat{d}-d_{o}\right) \rightarrow_{d} \quad N(0,1 / 4) \quad \text { as } T \rightarrow \infty
$$

where $d_{o}$ is the true value of $d$, with the only additional requirement that $\mathrm{m} \rightarrow \infty$ slower than T. Robinson (1995a) showed that m must be smaller than T/2 to avoid aliasing effects.

\section{The order of integration of the volatility of asset returns}

The data analysed in this section are the daily exchange rate and stock return series used by Wright (1999). The exchange rate series are the US dollar/UK pound, the US dollar/Deutschmark and the US dollar/Japanese yen obtained from Datastream, daily, over the calendar years 1986-1996 inclusive. The exchange rate returns were constructed as the first differences of the log exchange rates. The stock return data consist of the daily changes of the log of the SP/500 index, covering the period from 4 January 1982 to 23 September 1994.

\footnotetext{
1 Velasco (1999) has recently shown that the fractionally differencing parameter can also be consistently estimated semiparametrically in nonstationary contexts by means of tapering. See also Phillips and Shimotsu (2005) for an exact Whittle estimate.
} 


\section{(Insert Figures 1 and 2 about here)}

The procedure described in Section 2 is used to estimate the order of integration of the volatility of each of these series. More precisely, denoting the log-squares of each of the returns by $\mathrm{y}_{\mathrm{t}}{ }^{*}$, we estimate $\mathrm{d}$ according to (3). The results for the whole range of values of $\mathrm{m}$ (from $\mathrm{m}=1, \ldots, \mathrm{T} / 2$ ) are given in Figure $1 .^{2}$ It can be seen that for all four series the values of $d$ are very sensitive to the choice of $m$, especially if $m$ is small, which may be an indication of the presence of short-run dynamics in these series. We also show in Figure 1 the $95 \%$ confidence interval corresponding to the $\mathrm{I}(0)$ hypothesis. We observe that all estimates are above the interval, implying long-memory behaviour. In Figure 2 we display the same estimates but for a shorter range of values of m. One can see that the largest estimates are obtained for the US dollar/UK pound series, with d fluctuating around 0.25. For the remaining series, the values of $\mathrm{d}$ appear to be slightly smaller, ranging around 0.15.

\section{Conclusions}

In this article we have examined the stochastic volatility of several exchange rates and stock returns by using the local Whittle semiparametric approach proposed by Robinson (1995a) to estimate the order of integration of the log of the squared returns. This was motivated by an earlier study by Wright (1999), who concluded that even unit root tests not suffering from size distortions still lead to strong rejections of nonstationarity in volatility, implying that fractionally integrated models may provide a better representation of such highly persistent processes. Our results indicate that, indeed, in all cases volatility can be

\footnotetext{
${ }^{2}$ Some methods to calculate the optimal bandwidth numbers are examined in Delgado and Robinson (1996) and Robinson and Henry (1996). However, in the case of the Whittle estimator, the use of optimal values has not been theoretically justified. Other authors, such as Lobato and Savin (1998), use an interval of values for $\mathrm{m}$, but we have preferred to report the results for the whole range of values of $\mathrm{m}$.
} 
specified in terms of $\mathrm{I}(\mathrm{d})$ statistical models, the parameter $\mathrm{d}$ being around 0.25 in the case of the US dollar/UK pound exchange rate, and slightly smaller ( $\mathrm{d} \sim 0.15)$ for the US dollar/ Deutsch mark, the US dollar/Japanese yen and the SP/500 series.

As mentioned before, there also exist parametric methods for estimating and testing the fractional differencing parameter (see, eg., Gil-Alana and Robinson, 1997). In a recent paper, Gil-Alana (2003) takes such an approach to test for the presence of unit and fractional roots in the same volatility series as in the present study, and concludes that the four processes are $\mathrm{I}(\mathrm{d})$, the null hypothesis of $\mathrm{d}=0$ being strongly rejected in favour of long-memory alternatives $(\mathrm{d}>0)$. However, as pointed out in Section 2, estimation based on parametric procedures has the drawback of potential misspecification, and therefore semiparametric approaches such as the one used in this article are preferable. Other semiparametric methods (e. g., the average periodogram estimator (Robinson, 1994) and the log-periodogram regression estimator (Robinson, 1995b)) have been applied to other economic time series (see, eg. Gil-Alana, 2002). Investigating the sensitivity of the results to using alternative semiparametric approaches represents an interesting topic for further research. 


\section{References}

Bollerslev, T.R., Y. Chou and K.F. Kroner, 1982, ARCH models in finance: a selective review of the theory and empirical evidence, Journal of Econometrics 52, 5-59.

Bollerslev, T.R., F. Engle and D.B. Nelson, 1994, 'ARCH models', in R.F. Engle and D.L. McFadden eds. Handbook of Econometrics, Vol. 4, Elsevier, Amsterdam.

Delgado, M.A. and P.M. Robinson, 1996, Optimal spectral bandwidth for long memory. Statistica Seneca, 6, 97-112.

Dickey, D.. and W.A. Fuller, 1979, Distributions of the estimators for autoregressive time series with a unit root, Journal of the American Statistical Association 74, 427-431.

Gil-Alana, L.A., 2002, Semiparametric estimation of the fractional differencing parameter in the UK unemployment, Computational Economics 19, 323-339.

Gil-Alana, L.A., 2003, Fractional integration in the volatility of asset returns, European Review of Economics and Finance 2, 41-52.

Gil-Alana, L.A. and P.M. Robinson, 1997, Testing of unit roots and other nonstationary hypotheses in macroeconomic time series, Journal of Econometrics 80, 241-268.

Hansen, B.E., 1995, Regression with nonstationary stochastic volatility, Econometrica 63, 1113-1132.

Harvey, A.C., E. Ruiz and N.G. Shephard, 1994, Multivariate stochastic variance models, Review of Economic Studies 63, 435-463.

Lobato, I.N. and N.E. Savin, 1998, Real and spurious long memory properties of stock market data. Journal of Business and Economic Statistics, 16, 261-283.

Pantula, S.G., 1991, Asymptotic distributions of unit-root tests when the process is nearly stationary, Journal of Business and Economic Statistics 9, 63-71.

Perron, P. and S. Ng, 1996, Useful modifications to some unit root tests with dependent errors and their local asymptotic properties, Review of Economic Studies 63, 435-463.

Phillips, P.C.B. and P. Perron, 1988, Testing for a unit root in a time series regression, Biometrika 75, 335-346.

Phillips, P.C.B. and K: Shimotsu, 2005, Exact local Whittle estimation of fractional integration, forthcoming in Annals of Statistics.

Robinson, P.M., 1994, Time series with strong dependence, In C.A. Sims ed., Advances in Econometrics: Sixth World Congress, Vol 1, 47-95, Cambridge University Press. 
Robinson, P.M., 1995a, Gaussian semiparametric estimation of long range dependence, Annals of Statistics 23, 1630-1661.

Robinson, P.M., 1995b, Log-periodogram regression of time series with long range dependence, Annals of Statistics 23, 1048-1072.

Robinson, P.M. and M. Henry, 1996, Bandwidth choice in Gaussian semiparametric estimation of long-range dependence. P.M. Robinson and M. Rosenblatt eds. Athens Conference on Applied Probability in Time Series Analysis, Vol.II, New York, 220-232.

Ruiz, E., 1994, Quasi maximum likelihood estimation of stochastic volatility models, Journal of Econometrics 63, 289-306.

Schwert, G.W., 1989, Tests for unit roots: A Monte Carlo investigation, Journal of Business and Economic Statistics 7, 147-160.

Velasco, C., 1999, Gaussian semiparametric estimation of nonstationary time series, Journal of Time Series Analysis 20, 87-127.

Wright, J., 1999, Testing for a unit root in the volatibility of asset returns, Journal of Applied Econometrics 14, 309-318. 


\section{FIGURE 1}

Estimates of $d$ (Robinson, 1995a) in the volatility process for the whole range of values of $\mathrm{m}$

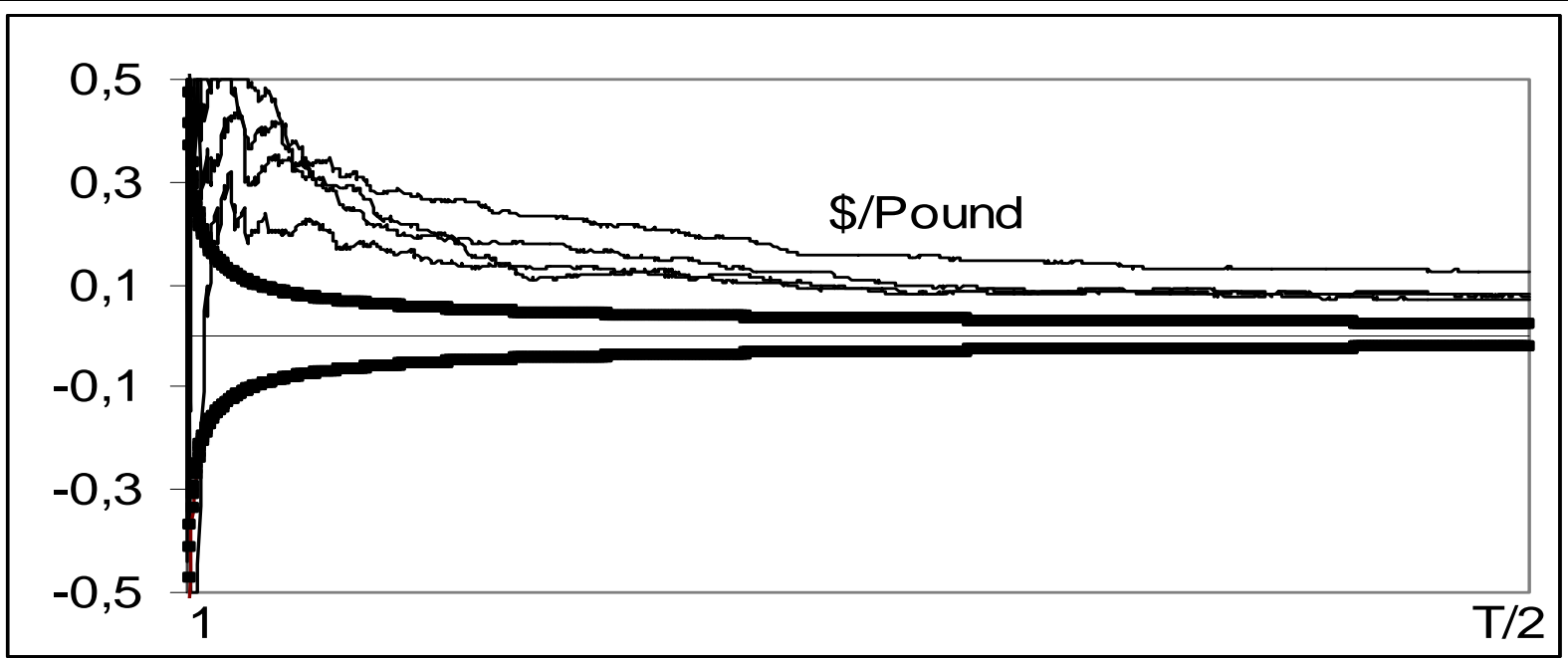

The horizontal axis corresponds to the bandwidth parameter number m, whilst the vertical one refers to the order of integration.

\section{FIGURE 2}

Estimates of d (Robinson, 1995a) in the volatility process for a shorter range of values of $\mathrm{m}$

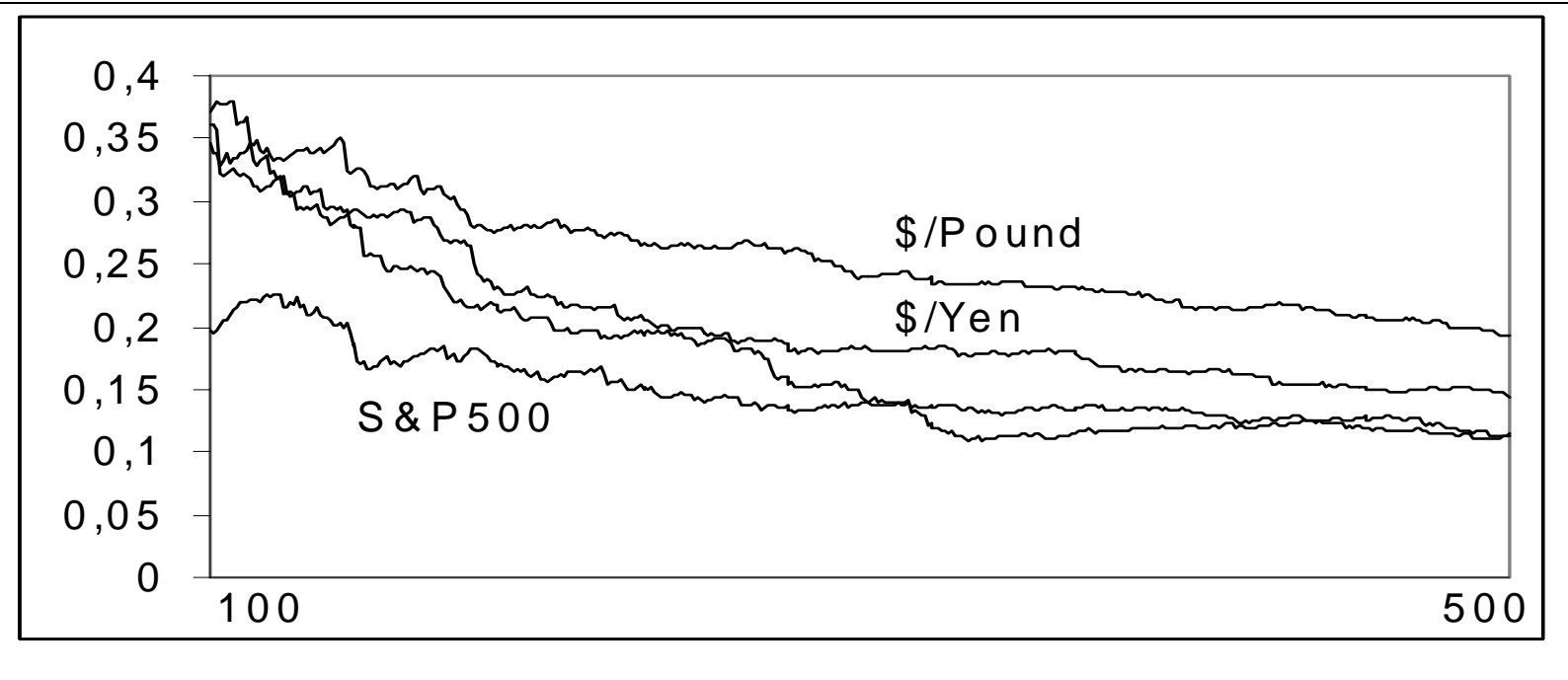

The horizontal axis corresponds to the bandwidth parameter number $\mathrm{m}$, whilst the vertical one refers to the order of integration. 